SIR-Alun Anderson's News article (Nature 321, 799; 1986) on the move of the Royal Greenwich Observatory (RGO) neglected to report that the Science and Engineering Council (SERC) also considered the possibility of moving it to Manchester. In fact, Manchester presented a powerful case, so why will RGO not move here?

SERC found the merits of Cambridge and Manchester to be finely balanced but simply considered the Cambridge case "to be even stronger". A world-beating centre of excellence is clearly what it was seeking, but that should not automatically favour Cambridge. The recent review by the University Grants Committee (UGC) rated Manchester's Physics and Astronomy Department, including Jodrell Bank, as outstanding, and here RGO would have formed the nucleus of a centre every bit as excellent as that we can expect in Cambridge. Did a beleaguered regional university just lose to the charisma of the old establishment?

An important inconsistency in the council's reasoning is that while claiming to be planning for the $1990 \mathrm{~s}$, it has allowed itself to be unduly influenced by the short-term consideration of minimizing disruption. Moreover, it does not give any reasons why the disruption caused by a move to Manchester should exceed that of a move to Cambridge. Could this be prejudice by the staff of RGO itself?

Alun Anderson's worries about costs are very relevant, but here Manchester had a strong advantage which was ignored. Construction of a new building to house RGO in Cambridge was apparently considered no more expensive than minor internal alterations to the suitable vacant premises in Manchester.

The council blithely asserts that both Manchester and Cambridge "have excellent communications" - sweeping Manchester's overwhelming superiority in this regard under the rug. The RGO staff will have to make regular trips to the new observatory in the Canary Islands; Manchester's international airport offers frequent direct flights and is just 20 minutes' drive from the university, whereas Cambridge to Gatwick airport is a long and awkward journey. It will be many years before Stansted will offer a service as good as already exists from Manchester. In addition, Manchester's rail and motorway connections to the rest of the country are far superior, which, together with its more central geographical location, would make RGO here much more readily accessible to astronomers around the country.

But the most disappointing aspect in my view is the missed opportunity for some positive action to redress the north/south economic imbalance. The number of new jobs at stake is rather small, but the relocation of an influential and sophisticated scientific research organization to the north-west would be a morale-boosting statement of confidence in northern science and industry. Its demands for local specialized high technology, computer software and so on would be of much greater industrial benefit here than in the already thriving area around Cambridge.

We may never know what clinched the decision in favour of the old university and the south. But we should be told because it caused extra expense and could be to the lasting detriment of British astronomy outside Cambridge.

Department of Astronomy,

JERry SELLWOOD

The University,

Manchester M13 9PL, UK

\section{Prehistoric protection}

SIR-The letter by Fernandez and others' on radon in the Altamira cave shows how lax the standards of radiation safety were in Europe before $10,000 \mathrm{BC}$. Assuming that they worked a 40 -hour week, I estimate that the palaeolithic painters received an annual radiation dose of 130 $\mathrm{mSv}$ from radon daughters. This would not be permitted under the Euratom legislation to which the European Community is now subject ${ }^{2}$ : the dose limit for workers is $50 \mathrm{mSv}$ in a year and indeed all exposures must be kept as low as reasonably achievable.

National Radiological Protection Bord,

Chilton, Didcot,

Oxfordshire $O X 110 R Q, U K$

I. Fernández, P.L. et al. Nature 321, 586 - 588 (1986)

. Official Journal of the European Communities, No. L.246/1, 17 September 1980.

\section{Speaking up}

SIR-David Swinbanks (Nature 321, 374; 1986) seems to doubt the relevance of the speech I made when accepting the Japan Prize.

An example of scientists not speaking up in time was the destruction by a Christian mob, around $A D 415$, of the famous library in Alexandria. That event set back civilization 1,000 years.

If third-century scientists had been able to enlighten the public, and if the government and the clergy had spoken out loudly and clearly at every opportunity, that set back would not have occurred. If we do not speak up now, our civilization may be destroyed for more than 1,000 years.

While in Japan, I learned that the United States is expected to provide a great deal of money for research for the
Strategic Defense Initiative (SDI) by West Germany (25 per cent), Great Britain (18 per cent) and Japan (13 per cent). The preliminary budget is $\$ 60,000$ million simply for research; development is not mentioned. You cannot blame the British Prime Minister for not refusing a subsidy to the British economy of 18 per cent of $\$ 60,000$ million.

President Dwight Eisenhower warned against the military-industrial complex, which has a momentum of its own. It has now extended far beyond the United States.

I also said in Japan that President Reagan has a better chance of achieving a nuclear freeze and a reduction of the nuclear arms race than any previous president. He should be told what scientists feel.

Division of Artificial Organs,

Department of Surgery,

University of Utah, Dumke Building, Salt Lake City, Utah 84112, USA

\section{Screwworm fly}

SIR-In the past twenty years, despite one or two minor setbacks, the New World screwworm fly, Cochliomya hominivorax, has been eliminated from the southern United States and all but the most southern areas of Mexico. It is difficult to accept that this is due, as suggested by J.L. Readshaw (Nature 320, 407; 1986), solely to climatic conditions adverse to the survival of the fly during this period. It is surely more than a coincidence that this occurred concurrently with the major sterile insect release method eradication campaign in the region.

This campaign, by the US Department of Agriculture, has apparently eliminated this major agricultural pest, which caused losses of many million dollars to cattle ranchers in the southern United States and Mexico.

A related species, Chrysomya bezzi$a n a$, widespread in South-East Asia and Papua New Guinea, is one of the most serious exotic animal disease threats to Australia. The United States has been most generous in sharing sterile insect release technology. This has enabled Australia to develop methods which it is hoped will be effective in eradicating any incursion of Chrysomya bezziana into this country. Whatever the beneficial effects of climate to the North American programme, the tropical climate in northern Australia has convinced us that rapid application of the US technology would be our major defence response.

Australian Agricultural Health and R.W. GEE

Quarantine Service,

Department of Primary Industry, Barton, ACT 2600,

Australia 